\section{Efektifitas Teknik Relaksasi Nafas Dalam dan Pijatan Effleurage terhadap penurunan skala nyeri pada post sectio caesarea}

The Effectiveness of Deep Breath Relaxation Technique and Effleurage Massage on decreasing pain scale in post sectio caesarea

\author{
Siti Rochimatul \\ Lailiyah.,S.SiT.,M.Kes.; Henny \\ Pertiwi.,S.Tr.Keb*) \\ *) Sekolah Tinggi IImu Kesehatan \\ (STIKes) Ngudia Husada Madura
}

\begin{abstract}
Deep breathing relaxation techniques and massage techniques is an act that can reduce the pain in postpartum mother sectio caesarea. The purpose of this study was to determine the difference in the intensity of post operative pain sectio caesarea with the technique of deep breathing relaxation and massage at irna C RSUD Syarifah Ambami Rato Ebu Bangkalan.
\end{abstract}

This study uses an experimental quasi approach. The population is patients who have severe pain, moderate pain, and mild pain after surgery sectio caesarea in irna C RSUD Syarifah Ambami Rato Ebu Bangkalan as many as 57 patients. 10-19 year old girls. the sample of 9 respondents who taught the technique of deep breathing relaxation and 9 respondents in giving massage techniques. sampling technique that is used is probability sampling. Data collection using SOP and pain scale sheets. Data analysis using paired t-test.

The results showed that of the 9 respondents most respondents after the technique of breath relaxation in light weight scale as much as 7 (77.8\%) postpartum. And from 9 respondents most of respondent after done massage technique of light weight scale as much as 8 (89.9) postpartum. Wilcoxon test results show probability value greater than expected significant value $(0.317<0.05)$. This means there is no difference in the intensity of postoperative postoperative pain of caesarea with the application of deep breathing relaxation and massage Effleurage.

Deep breathing relaxation techniques and massage techniques are important factors in preventing the occurrence of severe pain. postpartum is expected to post sectio caesarea to familiarize with the technique of deep breathing relaxation and massage techniques to reduce pain..

Keywords : technique of deep breathing relaxation, Effleurage, after surgery sectio caesarea pain

Correspondence : Siti Rochimatul Lailiyah, Jl. R.E. Martadinata Bangkalan, Indonesia.

\section{PENDAHULUAN}

Sectio Caesarea adalah melahirkan janin dengan irisan pada dinding perut (laparotomi) dan dinding uterus (histerektomi). Menurut World Health Organization (WHO) angka persalinan dengan metode sectio caesarea cukup besar yaitu mencapai $24 \%$ sampai $30 \%$ dari semua proses persalinan. Di Indonesia persentasinya masih besar yaitu lebih dari $50 \%$ dan semakin meningkat angkanya setiap tahunnya.

Nyeri post operasi Sectio Caesarea merupakan sensasi yang rumit, unik, universal, dan bersifat individual. Dikatakan bersifat individual karena respons individu terhadap sensasi nyeri beragam dan tidak bisa disamakan satu dengan yang lainnya(Sihombing et al., 2017).

$$
\text { Berdasarkan hasil }
$$

studi

pendahuluan bulan Maret 2017 di Irna C - RSUD Syarifah Ambami Rato Ebu 
Bangkalan, pada 6 bulan terakhir September 2016-Februari 2017 dari 120 persalinan dengan sectio caesarea 57 $(47,5 \%)$. Terdapat 5 ibu post operasi sectio caesarea hari kedua. Dengan menggunakan Skala nyeri verbal descriptor scale (VDS), terdapat 4 ibu post op. SC (80\%) mengemukakan nyeri yang dirasakan saat ini termasuk dalam nyeri berat. Sedangkan 1 ibu post op. SC $(20 \%)$ mengemukakan merasakan nyeri sedang.

Persalinan secara bedah sesar sering kali dihubungkan dengan nyeri pasca operasi. Suatu proses pembedahan setelah operasi atau post operasi akan menimbulkan respon nyeri. Nyeri yang dirasakan oleh ibu post partum dengan bedah sesar berasal dari luka yang terdapat pada perut. Tingkat dan keparahan nyeri pasca operasi tergantung pada fisiologis dan psikologis individu serta toleransi yang ditimbulkan nyeri(Kumaat, no date).

Ada 2 faktor penyebab nyeri pasca operasi sectio caesarea yaitu faktor internal yang terdiri dari ambang nyeri, pengalaman, usia, karakter ibu, kondisi insisi, dan kondisi psikologis(Apriansyah, Romadoni and Andrianovita, 2015). Sedangkan faktor eksternal yang mempengaruhi terdiri dari tenaga kesehatan, lingkungan, kebudayaan, dukungan, dan persiapan praoperatif (Sihombing et al., 2017).

Dampak fisiologis apabila tidak dilakukan kontrol nyeri, nyeri yang hebat menstimulasi respon stres yang secara merugikan mempengaruhi sistem jantung dan imun. Ketika impuls nyeri ditransmisikan, ketegangan otot meningkat seperti halnya vasokonstriksi lokal. Iskemia pada tempat yang sakit dapat menyebabkan stimulasi yang jauh dari reseptor nyeri. Bila impuls yang menjalar secara sentral, aktivitas simpatis diperberat, yang meningkatkan kebutuhan miokardium dan konsumsi oksigen. Riset telah menunjukkan bahwa insufisiensi kardiovaskular terjadi tiga kali lebih sering dan insiden infeksi lima kali lebih besar pada individu dengan kotrol nyeri yang buruk. Respon stres hipotalamik juga bertanggung jawab terhadap peningkatan viskositas darah dan agregasi trombosit, hal ini dapat mengarah pada flebotrombosis dan embolisme pulmonal.
Dampak sosial dapat menimbulkan kesulitan aktifitas pada ibu nifas sehingga mobilisasi terganggu yang dampaknya ke arah penyembuhan luka dan proses involusi yang terganggu. Selain itu juga dapat menyebabkan perawatan bayii oleh ibu yang terganggu sehingga proses bonding attachment antara ibu dan bayinya menjadi terganggu. Nyeri post yang berlebihan juga akan menyebabkan terjadinya kecemasan dan kualitas tidur klien('793-1553-1SM.pdf', no date)

\section{METODE PENELITIAN}

Jenis penelitian yang digunakan adalah penelitian eksperimental quasi dengan pendekatan Randomized pretest-post test control group design. Dalam penelitian ini variabel independent adalah pijat bayi dan variabel dependent adalah perkembangan bayi pada usia 3-4 bulan. Sampel pada kelompok yang tidak dilakukan pijat bayi maupun dilakukan pijat bayi, masing-masing sejumlah 15 bayi usia 3-4 bulan dengan menggunakan teknik sampling Simple Random Sampling. Uji statistik yang digunakan yaitu Wilcoxon Signed Ranks dan Mann-Whitney Test.

\section{HASIL PENELITIAN}

\section{Perbedaan skala nyeri post SC antara sebelum dan sesudah diberikan teknik relaksasi nafas dalam \\ Tabel 1. Distribusi frekuensi} berdasarkan skala nyeri post SC antara sebelum dan sesudah diberikan teknik relaksasi nafas dalam di Ruang IRNA C RSUD Syarifah Ambami Rato Ebu Bangkalan Pada Bulan Agustus 2017.

\begin{tabular}{|c|c|c|c|c|c|}
\hline $\begin{array}{l}\mathrm{N} \\
\mathrm{o} .\end{array}$ & $\begin{array}{l}\text { Ska } \\
\text { la } \\
\text { Nye } \\
\text { ri } \\
\text { Pret } \\
\text { est }\end{array}$ & $\begin{array}{c}\text { Skal } \\
\text { a } \\
\text { Nyer } \\
\text { i } \\
\text { Post } \\
\text { test }\end{array}$ & $\begin{array}{l}\text { Seli } \\
\text { sih }\end{array}$ & $\begin{array}{c}\text { Perse } \\
\text { ntase } \\
(\%)\end{array}$ & $\begin{array}{l}\text { Ketera } \\
\text { ngan }\end{array}$ \\
\hline 1 & 4 & 3 & 1 & 11.1 & $\begin{array}{c}\text { Menur } \\
\text { un }\end{array}$ \\
\hline 2 & 4 & 3 & 1 & 11.1 & $\begin{array}{c}\text { Menur } \\
\text { un }\end{array}$ \\
\hline
\end{tabular}




\begin{tabular}{|c|c|c|c|c|c|}
\hline 3 & 3 & 3 & 0 & 0 & $\begin{array}{c}\text { Menet } \\
\text { ap }\end{array}$ \\
\hline 4 & 4 & 3 & 1 & 11.1 & $\begin{array}{c}\text { Menur } \\
\text { un }\end{array}$ \\
\hline 5 & 4 & 3 & 1 & 11.1 & $\begin{array}{c}\text { Menur } \\
\text { un }\end{array}$ \\
\hline 6 & 3 & 2 & 1 & 11.1 & $\begin{array}{c}\text { Menur } \\
\text { un }\end{array}$ \\
\hline 7 & 4 & 4 & 0 & 0 & $\begin{array}{c}\text { Menet } \\
\text { ap }\end{array}$ \\
\hline 8 & 4 & 3 & 1 & 11.1 & $\begin{array}{c}\text { Menur } \\
\text { un }\end{array}$ \\
\hline 9 & 3 & 3 & 0 & 0 & $\begin{array}{c}\text { Menur } \\
\text { un }\end{array}$ \\
\hline
\end{tabular}

Menetap : $3(33.3 \%)$

Menurun : $6(66.7 \%)$

Uji statistik : Paired T-Test

Asymp Sign : 0,001

Sumber : Data Primer 2017

Berdasarkan tabel 1 menunjukkan nyeri post SC sebelum diberikan teknik relaksasi nafas dalam sebagian besar mengalami nyeri berat yaitu 6 responden $(66.7 \%)$ dan sesudah diberikan teknik relaksasi nafas dalam hampir seluruhnya mengalami nyeri sedang yaitu 7 responden (77.8\%).

Kemudian dilakukan uji statistik Paired T-Test karena distribusi normal didapatkan hasil $\rho$ value $<\alpha$ atau $(0,004$ $<0,05)$ sehingga $H_{1}$ diterima. Hal ini menunjukkan bahwa ada perbedaan skala nyeri post SC antara sebelum dan sesudah diberikan tekni relaksasi nafas dalam..

2. Perbedaan skala nyeri post SC antara sebelum dan sesudah diberikan teknik pijatan

Tabel 2. Distribusi frekuensi berdasarkan skala nyeri post SC antara sebelum dan sesudah diberikan teknik pijatan di Ruang IRNA C RSUD Syarifah Ambami Rato Ebu Bangkalan Pada Bulan Agustus 2017.

\begin{tabular}{|c|c|c|c|c|c|}
\hline $\begin{array}{l}\mathrm{N} \\
\mathrm{o} .\end{array}$ & $\begin{array}{l}\text { Ska } \\
\text { la } \\
\text { Nye } \\
\text { ri } \\
\text { Pret } \\
\text { est }\end{array}$ & $\begin{array}{c}\text { Skal } \\
\text { a } \\
\text { Nyer } \\
\text { i } \\
\text { Post } \\
\text { test }\end{array}$ & $\begin{array}{l}\text { Seli } \\
\text { sih }\end{array}$ & $\begin{array}{c}\text { Perse } \\
\text { ntase } \\
(\%)\end{array}$ & $\begin{array}{l}\text { Ketera } \\
\text { ngan }\end{array}$ \\
\hline 1 & 4 & 3 & 1 & 11.1 & $\begin{array}{c}\text { Menur } \\
\text { un }\end{array}$ \\
\hline 2 & 4 & 3 & 1 & 11.1 & $\begin{array}{c}\text { Menur } \\
\text { un }\end{array}$ \\
\hline
\end{tabular}

\begin{tabular}{|c|c|c|c|c|c|}
\hline 3 & 4 & 3 & 1 & 11.1 & $\begin{array}{c}\text { Menur } \\
\text { un }\end{array}$ \\
\hline 4 & 4 & 3 & 1 & 11.1 & $\begin{array}{c}\text { Menur } \\
\text { un }\end{array}$ \\
\hline 5 & 4 & 3 & 1 & 11.1 & $\begin{array}{c}\text { Menur } \\
\text { un }\end{array}$ \\
\hline 6 & 5 & 4 & 1 & 11.1 & $\begin{array}{c}\text { Menur } \\
\text { un }\end{array}$ \\
\hline 7 & 4 & 3 & 1 & 11.1 & $\begin{array}{c}\text { Menur } \\
\text { un }\end{array}$ \\
\hline 8 & 3 & 3 & 0 & 0 & $\begin{array}{c}\text { Menet } \\
\text { ap }\end{array}$ \\
\hline 9 & 4 & 3 & 1 & 11.1 & $\begin{array}{c}\text { Menur } \\
\text { un }\end{array}$ \\
\hline
\end{tabular}

Menetap : $1(11.1 \%)$

Menurun : $8(88.9 \%)$

Uji statistik : Paired T-Test

Asymp Sign : 0,001

Sumber : Data Primer 2017

Berdasarkan tabel 2 menunjukkan nyeri post SC sebelum diberikan teknik pijatan seluruhnya mengalami nyeri berat yaitu 7 responden (77.8\%) dan sesudah diberikan teknik pijatan hampir seluruhnya mengalami nyeri sedang yaitu 8 responden (88.9\%).

Kemudian dilakukan uji statistik Paired T-Test karena distribusi normal didapatkan hasil $\rho$ value $<\alpha$ atau $(0,000$ $<0,05)$ sehingga $H_{1}$ diterima. Hal ini menunjukkan bahwa ada perbedaan skala nyeri post SC antara sebelum dan sesudah diberikan tekni pijatan.

3. Perbedaan skala nyeri post SC antara sebelum dan sesudah diberikan teknik relaksasi nafas dalam dan pijatan.

Tabel 3. Perbedaan skala nyeri post SC antara sebelum dan sesudah diberikan teknik relaksasi nafas dalam dan pijatan di Ruang IRNA C RSUD Syarifah Ambami Rato Ebu Bangkalan Pada Bulan Agustus 2017.

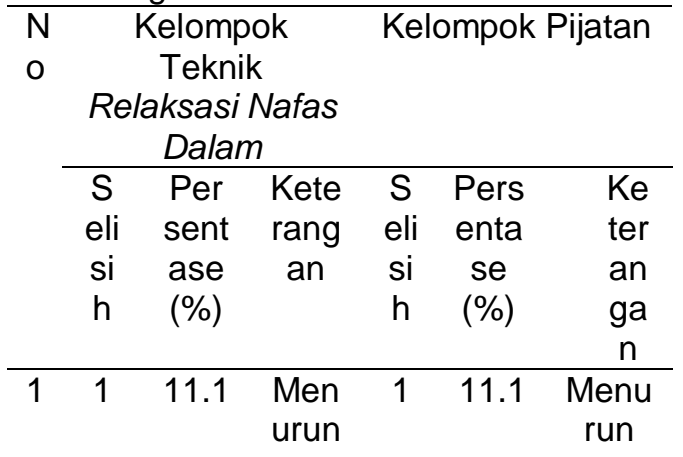




\begin{tabular}{|c|c|c|c|c|c|c|}
\hline 2 & 1 & 11.1 & $\begin{array}{l}\text { Men } \\
\text { urun }\end{array}$ & 1 & 11.1 & $\begin{array}{l}\text { Menu } \\
\text { run }\end{array}$ \\
\hline 3 & 0 & 0 & $\begin{array}{l}\text { Men } \\
\text { etap }\end{array}$ & 1 & 11.1 & $\begin{array}{l}\text { Menu } \\
\text { run }\end{array}$ \\
\hline 4 & 1 & 11.1 & $\begin{array}{l}\text { Men } \\
\text { urun }\end{array}$ & 1 & 11.1 & $\begin{array}{c}\text { Menu } \\
\text { run }\end{array}$ \\
\hline 5 & 1 & 11.1 & $\begin{array}{l}\text { Men } \\
\text { urun }\end{array}$ & 1 & 11.1 & $\begin{array}{l}\text { Menu } \\
\text { run }\end{array}$ \\
\hline 6 & 1 & 11.1 & $\begin{array}{l}\text { Men } \\
\text { urun }\end{array}$ & 1 & 11.1 & $\begin{array}{c}\text { Menu } \\
\text { run }\end{array}$ \\
\hline 7 & 0 & 0 & $\begin{array}{l}\text { Men } \\
\text { etap }\end{array}$ & 1 & 11.1 & $\begin{array}{l}\text { Menu } \\
\text { run }\end{array}$ \\
\hline 8 & 1 & 11.1 & $\begin{array}{l}\text { Men } \\
\text { urun }\end{array}$ & 0 & 0 & $\begin{array}{c}\text { Mene } \\
\text { tap }\end{array}$ \\
\hline 9 & 2 & 22.2 & $\begin{array}{l}\text { Men } \\
\text { urun }\end{array}$ & 1 & 11.1 & $\begin{array}{c}\text { Menu } \\
\text { run }\end{array}$ \\
\hline \multicolumn{7}{|c|}{$\begin{array}{l}\text { Uji Wilcoxon } \\
\rho: 0.317 \\
\alpha: 0.05\end{array}$} \\
\hline
\end{tabular}

Berdasarkan uji Paired T-Test dilakukan uji statistik Paired T-Test karena distribusi normal didapatkan hasil $\rho$ value $<\alpha$ atau $(0,004<0,05)$ sehingga $\mathrm{H}_{1}$ diterima. Hal ini menunjukkan bahwa ada perbedaan skala nyeri post SC antara sebelum dan sesudah diberikan tekni relaksasi nafas dalam.

Uji statistik Paired T-Test karena distribusi normal didapatkan hasil $\rho$ value $<\alpha$ atau $(0,000<0,05)$ sehingga $\mathrm{H}_{1}$ diterima. Hal ini menunjukkan bahwa ada perbedaan skala nyeri post SC antara sebelum dan sesudah diberikan tekni pijatan.

Uji Wilcoxon antara sebelum dan sesudah diberikan teknik relaksasi nafas dalam dan teknik pijatan menunjukkan nilai $\rho=0.317$ sehingga $\rho$ value $>\alpha=$ 0,05 sehingga $H_{1}$ ditolak $\mathrm{H} 0$ diterima yang berarti tidak ada perbedaan skala nyeri post SC antara sebelum dan sesudah diberikan teknik relaksasi nafas dalam dan teknik pijatan.

\section{PEMBAHASAN}

1. Perbedaan skala nyeri post SC antara sebelum dan sesudah diberikan teknik relaksasi nafas dalam

Berdasarkan hasil penelitian tentang Penurunan Nyeri Sebelum diberikan teknik relaksasi nafas dalam diketahui bahwa dari 9 responden sebagian besar mengalami nyeri berat yaitu 6 responden $(66.7 \%)$ dan sesudah diberikan teknik relaksasi nafas dalam diketahui bahwa dari 9 responden hampir seluruhnya mengalami nyeri sedang yaitu 7 responden ( $77.8 \%$ ).

Rasa nyeri merupakan mekanisme pertahanan tubuh, timbul bila ada jaringan rusak dan hal ini akan menyebabkan individu bereaksi dengan memindahkan stimulus nyeri. Seringkali dijelaskan dalam istilah proses distruktif, jaringan seperti ditusuk tusuk, panas terbakar, melilit, seperti emosi, perasaan takut, mual dan takut(Kasus et al., 2014).

Tekhnik relaksasi pernafasan merupakan suatu bentuk asuhan yang mengajarkan kepada pasien bagaimana cara melakukan nafas dalam, nafas lambat (menahan inspirasi secara maksimal) dan bagaimana menghembuskan nafas secara perlahan. Selain dapat menurunkan intensitas nyeri, Tekhnik relaksasi nafas juga dapat meningkatkan ventilasi alveoli dan meningkatkan oksigenasi darah. Sejauh ini relaksasi nafas dalam juga digunakan dalam menejemen stres, yakni sejenis terapi penanganan mental untuk menjauhkan tubuh dan pikiran dari stimulus luar.

Teknik relaksasi bernafas merupakan teknik pereda nyeri yang banyak mem- berikan masukan terbesar karena teknik relaksasi dalam persalinan dapat mencegah kesalahan yang berlebihan pasca persalinan. Adapun relaksasi bernapas selama proses persalinan dapat mempertahankan komponen sistem saraf simpatis dalam keadaan homeostasis sehingga tidak terjadi peningkatan suplai darah, mengurangi kecemasan dan ketakutan agar ibu dapat beradaptasi dengan nyeri selama proses persalinan.

Teknik relaksasi dapat dilakukan untuk mengendalikan rasa nyeri ibu dengan meminimalkan aktifitas simpatik dalam sistem saraf otonom. Ibu belajar untuk meningkatkan aktivitas komponen saraf parasimfatik vegetative yang lebih banyak secara simultan. Teknik tersebut dapat mengurangi sensasi nyeri dan mengontrol intensitas reaksi ibu terhadap rasa nyeri tersebut Teknik 
relaksasi nafas dalam dapat mengendalikan nyeri dengan meminimalkan aktifitas simpatik dalam sistem saraf otonom. Ibu meningkatkan aktifitas komponen saraf parasimpatik vegetatif secara simultan. Teknik tersebut dapat mengurangi sensasi nyeri dan mengontrol intensitas reaksi ibu terhadap rasa nyeri. Hormon adrenalin dan kortisol yang menyebabkan stres akan menurun, ibu dapat meningkatkan konsentrasi dan merasa tenang sehingga memudahkan ibu untuk mengatur pernafasan sampai frekuensi pernafasan kurang dari 60-70 $\mathrm{x} /$ menit. Kadar $\mathrm{PaCo} 2$ akan meningkat dan menurunkan $\mathrm{PH}$ sehingga akan meningkatkan kadar oksigen dalam darah. Seperti halnya nyeri pada persalinan, pada taraf yang ringan, nyeri yang dirasakan ini dapat membuat seseorang lebih memperhatikan kondisinya dan bayinya dengan mencari informasi dan pertolongan pada petugas kesehatan.

Hasil penelitian tersebut hampir sama dengan hasil penelitian terdahulu pada ibu bersalin kala I dengan hasil Hasil penelitian menunjukan bahwa sebelum diberikan teknik relaksasi genggam jari sebagian besar responden mengalami nyeri sedang sebanyak 9 responden dan sesudah diberikan teknik relaksasi genggam jari sebagian besar mengalami nyeri ringan 8 responden. . Ada perbedaan skala nyeri sebelum dan sesudah pada kelompok eksperimen dengan nilai $p$ value sebesar $0,001(p<$ $\alpha)$ (Caesarea, Rsud and Margono, no date).

Keuntungan utamanya, teknik relaksasi nafas dalam tersebut memberi perasaan yang rileks dalam mengontrol pernafasan sehingga dapat mengurangi rasa sakit bantu kelahiran dan pemulihan. Latihan pernafasan yang khusus biasanya jarang dianjurkan. Jika sudah terampil melakukan pernapasan dalam-dalam maka pembangunan latihan fisik dan pernafasan akan memberikan hasil yang lebih baik, metode psikoprofilaktik yaitu persiapan psikologis dan fisik menjelang persalinan atau disebut juga dengan metode lemaze atau metode lain untuk persalinan yang alami. Semua metode tersebut membutuhkan keterampilan bernafas sesuai dengan tahap-tahap pembukaan, penurunan kepala, kelahiran bayi(Fitriani et al., 2013).

Penelitian ini juga sejalan degan penelitian terdahulu dengan hasil sebagai berikut : pertama adalah sebelum dilakukan pemberian teknik relaksasi nafas dalam, sebagian besar pasien mengalami nyeri dengan skala intensitas nyeri pada skala 6 atau nyeri sedang. Kedua, setelah dilakukan pemberian teknik relaksasi nafas dalam, sebagian besar pasien mengalami nyeri dengan skala intensitas 3 atau nyeri ringan. Ketiga, sebelum dilakukan pemberian teknik relaksasi nafas dalam sebagian besar 26 responden mengalami nyeri sedang. Setelah dilakukan perlakuan pemberian teknik relaksasi nafas dalam sebagian kecil 18 responden mengalami nyeri ringan. Keempat, ada pengaruh signifikan pada pemberian teknik relaksasi nafas dalam terhadap tingkat nyeri pada pasien post operasi dengan anestesi umum di RSUD Dr. Moewardi Surakarta(Anestesi, Di and Moewardi, 2013).

Dari hasil penelitian didapatkan sebelum dilakukan teknik nafas dalam kebanyakan ibu nifas mengalami nyeri berat hal tersebut sesuai dengan hasil skala nyeri yang sudah dibagikan kepada ibu nifas dan kebanyakan ibu nifas menunjuk angka 8 pada lembar skala nyeri. Nyeri yang berat dapat disebabkan oleh faktor usia, dimana ibu yang post sc sebagian besar berusia 1822 tahun, dimana ibu dalam usia muda masih belum mempunyai pengalaman dalam hal melahirkan sehingga ibu belum merasa siap dalam menghadapi persalinan secara SC.

Maka berdasarkan penelitian ini dapat disimpulkan bahwa tehnik relaksasi dapat dijadikan teknik mopmplementer baik sebagai intervensi keperawatan dan kebidanan maupun sebagai upaya mandiri oleh klien untuk menurunkan nyeri post SC.

\section{Perbedaan skala nyeri post SC antara sebelum dan sesudah diberikan teknik pijatan}

Berdasarkan hasil penelitian tentang Penurunan Nyeri Sebelum diberikan teknik pijatan diketahui bahwa dari 9 responden hampir seluruhnya 
mengalami nyeri berat yaitu 7 responden (77.8\%) dan sesudah diberikan teknik pijatan diketahui bahwa dari 9 responden hampir seluruhnya mengalami nyeri sedang yaitu 8 responden (88.9\%).

Menurut mendefinisikan nyeri sebagai suatu fenomena yang sulit dipahami, kompleks, dan bersifat misteri yang mempengaruhi seseorang, serta eksistensinya diketahui bila seseorang mengalaminya. Nyeri adalah pengalaman yang tidak menyenangkan pada pasien pasca bedah. Cedera jaringan atau inflamasi akut akan menyebabkan pengeluaran berbagai mediator inflamasi seperti katekolamin, bradikinin, prostaglandin, histamine, 5hydroxytryptamine, leukotrien, amin, purin, sitokin, dan sebagainya yang dapat mengaktivasi atau mensensitisasi nosiseptor secara langsung atau tidak langsung. Pengelolaan nyeri pasca bedah yang optimal akan menurunkan morbiditas pasien. Tingginya angka morbiditas pasca bedah akan menyebabkan bertambahnya waktu penyembuhan, lama tinggal, dan menambah biaya rawat di rumah sakit. Pengelolaan nyeri pasca bedah yang optimal, bukan saja merupakan upaya mengurangi penderitaan penderita, tetapi juga meningkatan kualitas hidupnya. Telah terbukti bahwa tanpa pengelolaan nyeri paasca bedah yang adekuat, penderita akan mengalami gangguan fisiologis maupun psikologis yang pada gilirannya secara bermakna meningkatkan angka morbiditas dan mortalitas (Difference and Of, 2009).

Pijat effleurage adalah istilah untuk gerakan yang ringan dan menenangkan saat memulai dan mengakhiri pijatan. Gerakan ini bertujuan meratakan minyak dan menghangatkan otot agar rileks. Euffleurage terutama dilakukan dengan telapak tangan dan jemari rapat. Tangan harus mengikuti kontur tubuh saat meluncur diatasnya. Gerakan-gerakan euffleurage harus mengalir tanpa terputus dan menyambung berbagai tahap pemijatan. Biasanya gerakan ini dilakukan dengan tekanan lebih kuat saat mengarah ke jantung. Hal ini dimaksud untuk membantu peredaran darah dan getah bening. Saat kembali, gerakan harus dilakukan dengan usapan yang lebih ringan dan menenangkan (Aslany, 2003)

Massage effleurage adalah pijatan lambat perut atau bagian tubuh lain selama kontraksi. Ibu yang bersalin belajar untuk melakukan effleurage menggunakan kedua tangan dalam gerakan melingkar. Teknik ini menimbulkan efek relaksasi, dengan menggunakan usapan lembut dan ringan tanpa tekanan kuat, melibatkan interaksi yang kuat antara pikiran, tubuh dan jiwa. Massage effleurage dapat dikaitkan dengan teori gate control, dimana teori ini mengatakan bahwa sentuhan dan nyeri jika dirangsang bersamaan, sensasi sentuhan akan berjalan ke otak dan menutup pintu gerbang pada otak, sehingga ada pembatasan persepsi pada nyeri. Sentuhan ringan ini juga mempunyai efek distraksi dan meningkatkan hormon endorphin sehingga ibu yang mengalami nyeri pada persalinan merasakan kenyamanan karena adanya relaksasi otot (Studi et al., no date)

Pada persalinan, massage effleurage dilakukan dengan menggunakan ujung jari yang tidak putus-putus dari permukaan kulit, usapan dilakukan dengan ringan dan tanpa tekanan yang kuat. Seorang pendamping persalinan yang melakukan pemijatan bisa melakukan usapan menggunakan ujung-ujung jari telapak tangan dengan gerak arah membentuk pola gerakan seperti kupu-kupu pada abdomen seiring dengan pernafasan abdomen. Teknik tersebut bertujuan untuk meningkatkan sirkulasi darah, menghangatkan otot abdomen, memberi tekanan dan meningkatkan relaksasi fisik.

Mekanisme penghambatan nyeri persalinan dengan teknik Effleurage berdasarkan pada konsep teori Gate Control yang mengatakan bahwa stimulasi serabut taktil kulit dapat menghambat sinyal nyeri dari area tubuh yang sama atau area lainnya. Stimulasi serabut taktil kulit dapat dilakukan dengan teknik massage. Selama kontraksi berlangsung, impuls nyeri berjalan dari uterus sepanjang serabut saraf $C$ untuk ditransmisikan ke Substansia Gelatinosa di Spinal Cord dan disampaikan ke Cortex Cerebri untuk diterjemahkan sebagai nyeri. 
Stimulasi taktil dengan massage effleurage menghasilkan pesan yang sebaliknya dikirim lewat serabut saraf yang lebih besar (Serabut A Delta). Serabut A Delta akan menutup gerbang sehingga Cortex Cerebri tidak menerima pesan nyeri karena sudah diblokir oleh stimulasi dengan massage effleurage sehingga persepsi nyeri berubah, karena serabut dipermukaan kulit (Cutaneus) sebagian besar adalah serabut saraf yang berdiameter luas. Massage effleurage juga digunakan sebagai distraksi dan menurunkan transmisi sensorik stimulasi dari dinding abdomen sehingga mengurangi ketidaknyamanan pada area yang sakit. Sebagai teknik relaksasi, massage effleurage mengurangi ketegangan otot (Lowdermilk, Perry, \& Cashion, 2010) dalam (Studi et al., no date), meningkatkan sirkulasi area yang sakit dan mencegah terjadinya hipoksia. Massage dan sentuhan membantu ibu lebih rileks dan nyaman selama persalinan. Sebuah penelitian menyebutkan ibu yang dipijat selama 20 menit setiap jam selama tahapan persalinan akan lebih bebas dari rasa sakit, karena massage (pijat) merangsang tubuh melepaskan senyawa endhorpin yang merupakan pereda sakit alami dan menciptakan perasaan nyaman(Kesehatan et al., 2016).

4.

Pijat dapat menenangkan dan merilekskan ketegangan yang muncul saat hamil dan melahirkan. Pijatan pada leher, bahu, punggung, kaki, dan tangan dapat membuat nyaman. Usapan pelan pada perut juga akan terasa nyaman saat kontraksi, rencana untuk menggunakan pijatan atau sentuhan yang disukai dalam persalinan dapat dipilih sebagai berikut : sentuhan pelan dengan ketukan yang berirama, usapan keras, pijatan untuk melemaskan otototot yang kaku, dan pijatan keras atau gosokan di punggung

Berdasarkan hasil penelitian didapatkan sebelum dilakukan teknik pemijatan kebanyakan ibu nifas intensitas nyerinya berat, hal tersebut disebabkan oleh faktor jenis persalinan yang dahulu, yang mana kebanyakan ibu nifas masih pertama kali mempunyai anak dan baru merasakan jenis persalinan SC yang mana merupakan jenis persalinan pembedahan yang menggunakan obat anastesi dalam pelaksanaannya, sehingga menyebabkan rasa nyeri pada waktu pemulihan, dan pemulihannya lebih lama serta diwajibkan ibu nifas untuk melakukan mobilisasi dini agar rasa nyeri berkurang.

Dari hasil penelitian didapatkan bahwa ibu nifas sesudah dilakuka teknik pijat kebanyakan intensitas nyerinya sedang, hal tersebut disebabkan oleh faktor teknik nafas dalam yang sudah dilakukan ibu nifas, dimana dengan melakukan pijatan dapat menjadikan otot-otot yang sebelumnya kaku menjadi lemas sehingga dapat menyebabkan nyeri berkurang.

Hasil penelitian senada dengan penelitian terdahulu yaitu Responden yang mengalami penurunan tingkat nyeri sejumlah $26(92,9 \%)$ responden, dan yang mengalami tingkat nyeri tetap dua $(7,1 \%)$ responden. Dengan rata-rata sebelum dan sesudah dilakukan massage effleurage, yaitu sebelum dilakukan massage effleurage sebesar 5,9642 , dan rata-rata tingkat nyeri sesudah dilakukan massage effleurage sebesar 3,6071. Hasil analisa uji Wilcoxzon, menunjukan bahwa pemberian massage effleurage terhadap ibu inpartum kala kala 1 fase aktif, berpegaruh signifikan terhadap tingkat nyeri ibu inpartum kala 1 fase aktif, yaitu dengan nilai $Z$ hitung sebesar $-4,548$ dan nilai asymp. Sig sebesar 0,000 . Hal ini menunjukan bahwa nilai $p<0,05$ yang berarti Ho ditolak, dan Ha diterima yang artinya ada pengaruh pemberian teknik massage effleurage terhadap tingkat nyeri ibu inpartum kala 1 fase aktif(Kesehatan et al., 2016) pada kala I fase aktif mayoritas responden mengalami nyeri berat sehingga peneliti tertarik untuk memberikan terapi non farmakologis yaitu dengan melakukan massage effleurage pada abdomen untuk meredakan nyeri persalinan kala I fase aktif(Massage et al., no date).

Maka, hasil penelitian ini menunjukkan bahwa pijat euffleurage dapat direkomendasikan sebagai terapi mandiri atau komplementer dalam menurunkan nyeri post SC. 
3. Perbedaan skala nyeri post SC antara sebelum dan sesudah diberikan teknik relaksasi nafas dalam dan pijatan.

Hasil uji analisis statistik dengan menggunakan uji Paired T-Test menunjukkan bahwa nilai $\rho=0,004$ sehingga $\rho$ value $<\alpha=0,05$ sehingga $\mathrm{H}_{1}$ diterima $\mathrm{HO}$ ditolak yang berarti ada perbedaan skala nyeri post SC antara sebelum dan sesudah diberikan teknik relaksasi nafas dalam. Dan juga menunjukkan bahwa nilai $\rho=0,000$ sehingga $\rho$ value $<\alpha=0,05$ sehingga $\mathrm{H}_{1}$ diterima $\mathrm{HO}$ ditolak yang berarti ada perbedaan skala nyeri post SC antara sebelum dan sesudah diberikan teknik pijatan. Dan setelah dilakukan uji Wilcoxon antara sebelum dan sesudah diberikan teknik relaksasi nafas dalam dan teknik pijatan menunjukkan nilai $\rho=$ 0.317 sehingga $\rho$ value $>\alpha=0,05$ sehingga $\mathrm{H}_{1}$ ditolak $\mathrm{HO}$ diterima yang berarti tidak ada perbedaan skala nyeri post SC antara sebelum dan sesudah diberikan teknik relaksasi nafas dalam dan teknik pijatan. Dalam penelitian yang dilakukan peneliti dengan pemberian teknik relaksasi nafas dalam dan teknik pijatan selama 15 menit dalam 1 hari, pada ibu post SC mampu menurunkan skala nyeri sehingga ibu merasa nyaman dan tenang. Berdasarkan Brunner \&Suddart (2007) telah menunjukkan bahwa relaksasi nafas dalam sangat efektif dalam menurunkannyeri pasca operasi SC. Dalam teknik relaksasi nafas dalam dan pijatan pada ibu post operasi sectio caesarea ternyata kedua upaya penurunan nyeri tersebut sama-sama efektif untuk menurunkan nyeri post operasi sectio caesarea tetapi diantara keduanya lebih efektif relaksasi nafas dalam dibandingkan pijat.

Dari hasil uji yang dilakukan nilai mean sebelum dan sesudah dberikan teknik relaksasi nafas dalam sebesar 3.00. Sedangkan mean sebelum dan sesudah diberikan teknik pijatan sebesar 3.11. Terdapat perbedaan mean antara sebelum dan sesudah diberikan teknik relaksasi nafas dalam dan teknik pijatan. Dimana nilai teknik pijatan lebih tinggi dibanding dengan teknik relaksasi nafas dalam. Namun setelah dilakukan uji analisis statistik dengan menggunakan uji Paired T-Test menunjukkan bahwa teknik relaksasi nafas dalam mempunyai nilai $\rho=0,004$ sehingga $\rho$ value $>\alpha=0,05$. Dan teknik pijatan mempunyai nilai $\rho=0,000$ sehingga $\rho$ value $>\alpha=0,05$. Hal ini disebabkan karena persepsi nyeri oleh masing-masing responden, tidak homogennya usia dan paritas responden juga mempengaruhi skala nyeri yang dirasakan oleh pasien post SC. Berdasarkan hasil diatas dapat dipastikan tindakan yang lebih efektif untuk mengatasi nyeri pasien post SC adalah teknik pijatan.

Maka berdasarkan hasil penelitian dapat disimpulkan bahwa kedua intervensi sama-masa menurunkan skala nyeri. Maka dalam penerapannya di lapangan dapat dilakukan secara bersama-sama untuk meningkatkan efek penurunan skala nyeri.

\section{KESIMPULAN}

Berdasarkan hasil penelitian dapat di ambil kesimpulan sebagai berikut:

1. Sesudah dilakukan teknik relaksasi nafas dalam sebagian besar lbu nifas post SC di ruang IRNA C RSUD Syarifah Ambami Rato Ebu Bangkalan intensitas nyerinya ringan.

2. sesudah dilakukan teknik pijat sebagian besar lbu nifas post SC di ruang IRNA C RSUD Syarifah Ambami Rato Ebu Bangkalan intensitas nyerinya ringan.

3. Tidak ada perbedaan intensitas nyeri antara teknik relaksasi nafas dalam dengan teknik pijatan pada lbu nifas post SC di ruang IRNA C RSUD Syarifah Ambami Rato Ebu Bangkalan.

\section{DAFTAR PUSTAKA}

'793-1553-1-SM.pdf' (no date). Anestesi, D., Di, U. and Moewardi, R. (2013) 'Kata Kunci: Teknik relaksasi nafas, nyeri pasien post operasi', 3(1), pp. 52-60.

Apriansyah, A., Romadoni, S. and Andrianovita, D. (2015) 'HUBUNGAN ANTARA TINGKAT KECEMASAN PREOPERASI DENGAN DERAJAT NYERI PADA PASIEN POST SECTIO 
CAESAREA DI RUMAH SAKIT MUHAMMADIYAH PALEMBANG

TAHUN 2014', 2(2355), pp. 1-9.

Aslany, M. (2003) No Titleteknik pijat untuk pemula (petunjuk praktis seni memijat sendiri maupun berpasangan). Jakarta: Erlangga.

Caesarea, S., Rsud, D. I. and Margono, P. (no date) 'PERUBAHANSKALA NYERI PADA PASIEN POST OPERASI', pp. 64-71.

Difference, T. H. E. and Of, E. (2009) 'DEKSKETOPROFEN SEBAGAI ANALGESIA PASCA BEDAH PROGRAM PENDIDIKAN DOKTER SPESIALIS I'.

Fitriani, R. et al. (2013) 'Pengaruh teknik relaksasi nafas dalam terhadap respon adaptasi nyeri pada pasien inpartu kala $i$ fase laten di rskdia siti fatimah makassar tahun 2013'.

Kasus, S. et al. (2014) 'Manajemen nyeri menggunakan terapi musik pada pasien post', 2 .

Kesehatan, J. et al. (2016) 'Sri Handayani , "Massage Effleurage Terhadap ...."', 07(02), pp. 122-132.

Kumaat, L. (no date) 'No Title'.

Massage, $P$. et al. (no date) 'PENGURANGAN TINGKAT NYERIPERSALINAN KALA I FASE', pp. 59-67.

Sihombing, N. et al. (2017) 'DETERMINAN PERSALINAN SECTIO CAESAREA DI INDONESIA ( ANALISIS LANJUT DATA RISKESDAS 2013 ) The Determinants of Sectio Caesarea Labor in Indonesia ( Further Analysis of Riskesdas 2013 ) I...', 8(1), pp. 63-75. doi: 10.22435/kespro.v8i1.6641.63-75.

Studi, P. et al. (no date) 'EFEKTIVITAS MASSAGE EFFLEURAGE YANG'. 